\title{
PERANCANGAN INTERAKSI MENGAMBIL OBYEK VIRTUAL DI AUGMENTED REALITY
}

\author{
Yuri Yudhaswana Joefrie \\ Jurusan Teknik Elektro \\ Kampus Bumi Tadulako Tondo \\ Jl. Sukarno Hatta Km. 9 Palu \\ Sulawesi Tengah 94111 \\ e-mail : yuri.yudhaswana@untad.ac.id
}

\begin{abstract}
This research promoted the topic concerning the interaction technique using virtual hand in Augmented Reality environment (AR). The kind of interaction researched uses tracker library that use marker to know the human gesture. This research results in virtual hand design that can be used to interact with virtual object. With the kind of interaction i.e. grab the virtual object and drop that grabbed virtual object to the place desired and the design of virtual hand that similar to the real,. So that it is expected virtual hand could be another alternative on how we interact in world of augmented reality.

\section{Kata kunci : Augmented Reality, Virtual Hand, Natural Gesture}

Penelitian ini mengangkat topik mengenai teknik interaksi dengan menggunakan tangan virtual dalam lingkungan Augmented Reality (AR). Jenis interaksi yang diteliti menggunakan tracker library yang berbasis marker untuk mengenali gerak tangan manusia. Penelitian ini menghasilkan tangan virtual yang dapat digunakan untuk berinteraksi dengan obyek virtual. Dengan jenis interaksi seperti mengambil obyek virtual dan menjatuhkan obyek virtual di tempat yang diinginkan dan rancangan tangan virtual yang mirip dengan kenyataan maka diharapkan model tangan virtual dapat menjadi alternatif dalam model interaksi di dunia augmented reality.
\end{abstract}

\section{Kata kunci : Augmented Reality, Tangan Virtual, Gerak Natural}

\section{PENDAHULUAN}

Saat perkembangan teknologi semakin meningkat, hal ini juga berpengaruh terhadap bidang computer vision. Definisi computer vision secara umum adalah merupakan ilmu dan teknologi bagaimana suatu machine/sistem melihat sesuatu. Masukan untuk suatu sistem berbasis computer vision adalah citra atau image. Data citra dapat berbentuk urutan video, citra dari kamera, dan lain-lain.

Beberapa hal yang dikerjakan oleh computer vision adalah recognition, motion, scene reconstruction, dan image restoration. Berikut beberapa contoh penerapan computer vision, yaitu controlling process, detecting events, organizing information, modeling objects or environtments, dan interaction (human-computer interaction).

Konsep dari computer vision juga digunakan dalam bidang augmented reality. Augmented reality adalah sebuah konsep tentang penggabungan dunia nyata dan komputer grafis. Tujuan dari augmented reality adalah menambahkan pengertian dan informasi dunia nyata dimana sistem augmented reality mengambil dunia nyata sebagai dasar dan mengabungkan beberapa teknologi dengan menambahkan data kontekstual agar pemahaman seseorang menjadi semakin jelas.

Kaufmann menyebutkan ada tiga karakteristik yang melekat pada augemented reality, yaitu: kombinasi dunia nyata dan virtual, interaksi berlansung secara real time, berbentuk 3D. Data kontekstual ini dapat berupa komentar audio, data lokasi, konteks sejarah, atau dalam bentuk- 
bentuk lain. Saat ini Augmented Reality (AR) telah banyak diaplikasikan dalam berbagai bidang seperti kedokteran, militer, manufaktur, hiburan, museum, game pendidikan dan lain-lain.

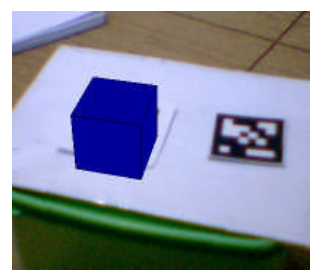

Gambar 1. Model virtual yang berdiri tepat di atas marker.

Untuk menjalankan sistem AR, minimal terdiri atas kamera, perangkat monitor, dan dalam kasus-kasus tertentu memerlukan perangkat khusus untuk berinteraksi dengan obyek virtual.

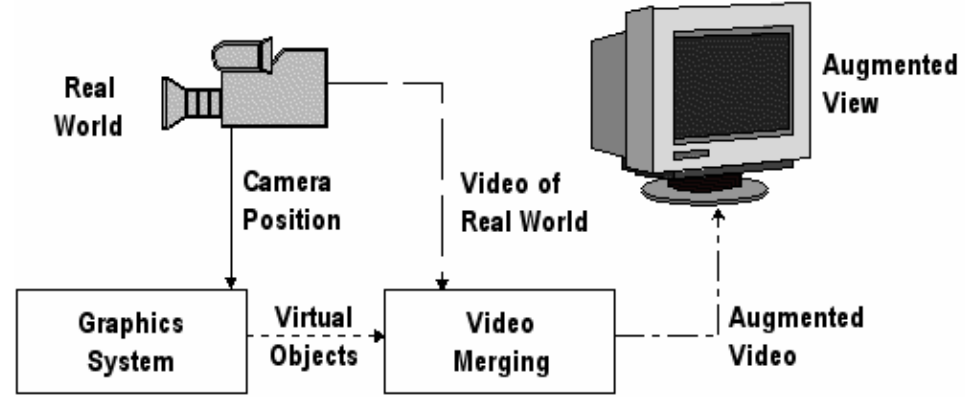

Gambar 2. Perangkat pendukung teknologi AR.

Perangkat monitor dapat diganti dengan perangkat video see-through untuk meningkatkan kesan impresif dari obyek virtual. Perangkat video see-through, biasa juga dinamakan head-mounted display (HMD), akan memenuhi seluruh sudut pandang pengguna, sehingga kesan nyata dapat tercapai.
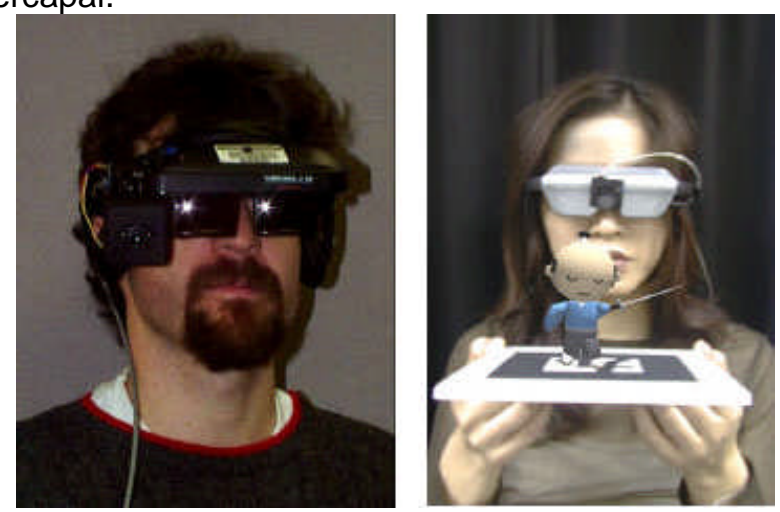

Gambar 3. Penggunaan HMD dalam sistem AR.

Untuk menggambar obyek virtual dalam dunia nyata, terdapat lima langkah seperti yang ditunjukkan dalam Gambar 4. 


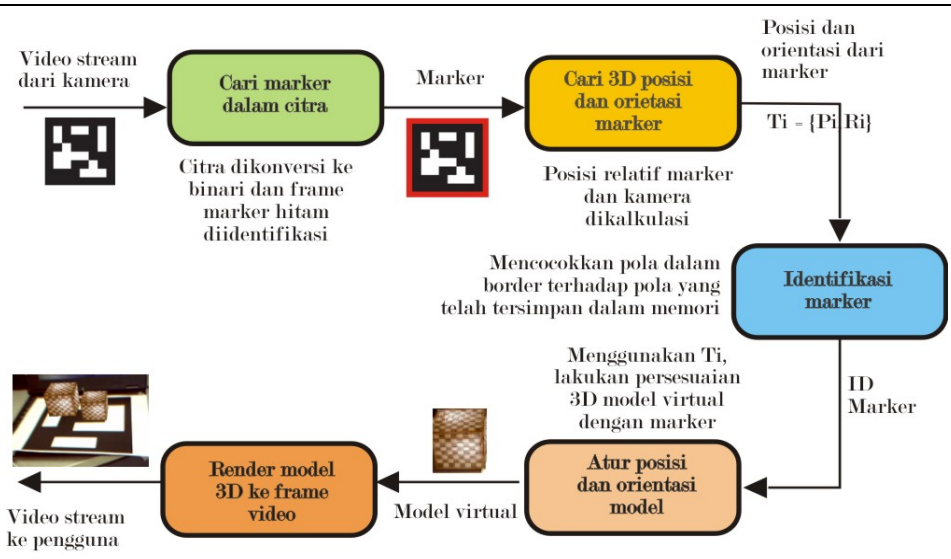

Gambar 4. Langkah-langkah untuk me-render obyek virtual dalam dunia nyata.

Pertama, hasil tangkapan citra dari kamera (webcam) diubah dalam bentuk binari (hitam atau putih) berdasarkan nilai threshold cahaya. Dalam citra ini kemudian dilakukan pencarian terhadap pola kotak. Kemungkinan ada beberapa kotak yang dikenali dalam tahap ini, namun tidak semua kotak tersebut adalah marker. Untuk setiap kotak yang terdeteksi, dilakukan kesesuaian terhadap marker yang sudah dilatih sebelumnya. Jika sesuai, maka ARToolKitPlus menemukan marker tracking atau fiducial marker. ARToolKitPlus kemudian menggunakan ukuran marker dan pola orientasi yang telah diketahui untuk menghitung posisi kamera relatif terhadap marker. Hasil dari perhitungan tersebut dimasukkan ke dalam matriks $3 \times 4$. OpenGL kemudian digunakan untuk me-render obyek virtual berdasarkan matriks $3 \times 4$ yang berisi nilai posisi kamera relatif terhadap marker dalam real world coordinates.

Untuk pendeteksian marker yang menjadi tanda dalam webcam dan perhitungan persesuaian obyek virtual dengan dunia nyata, digunakan pustaka ARToolKit Plus. Bersifat open source di bawah lisensi GPL dan mudah digunakan. ARToolKitPlus adalah pengembangan dari librari AR sebelumnya, yaitu ARToolKit yang dikembangkan oleh Hirokazu Kato di Hiroshima City University dan Mark Billinghurst di Human Interface Technology Laboratory New Zealand (HIT Lab NZ).

Menurut kajian penerapan interaksi dalam lingkungan augmented reality, secara umum, Gibet dalam bukunya yang berjudul "Gesture in Human Computer Interaction and Simulation" yang direview oleh Jacob Eisenstein, klasifikasi interaksi dapat dibagi menjadi dua, yaitu direct manipulation dan whole-gesture semaphore, yaitu yang berfungsi seperti tombol yang memicu tugas tertentu.

Dalam makalah "FingARtips - Gesture Based Direct Manipulation in Augmented Reality" oleh Buchmann, disebutkan bahwa interaksi terbagi menjadi dua berdasarkan ruang lingkupnya, yaitu ruang di dekat subyek dan ruang yang jauh dari subyek. Untuk obyek yang dekat dengan subyek, yaitu dalam jangkauan tangan, obyek dapat dimanipulasi secara intuitif. Sedangkan untuk obyek yang jauh dengan subyek, yaitu yang diluar jangkauan tangan, diperkenalkan teknik ray-based selection. Buchmann juga membahas mengenai interaksi dengan sistem AR menggunakan tangan virtual yang dilengkapi dengan haptic feedback berupa sarung tangan yang diberi alat elektronik sederhana sebagai penggetar. FingARtips mengeksplorasi mengenai kesederhanaan, kemudahan, dan sifat alami dalam berinteraksi. Namun, sepanjang pengamatan, fingARtips tidak ditujukan untuk berinteraksi dengan model virtual berdimensi kecil.

Dalam penelitian ini, masalah yang teridentifikasi adalah bagaimana merancang tangan virtual yang mampu untuk melakukan jenis interaksi mengambil obyek dalam dunia augmented reality.

Tujuan dari penelitian ini adalah membuat sistem tangan virtual yang interaktif dan natural untuk digunakan dalam lingkungan AR. Tangan virtual ini akan dirancang untuk mampu 
berinteraksi dalam hal mengambil obyek virtual yang berukuran relatif besar dan juga obyek yang berukuran relatif kecil. Tangan virtual ini akan berfungsi sebagaimana tangan manusia sehingga orang mampu menggunakannya tanpa perlu latihan terlalu lama.

\section{METODE PENELITIAN}

Agar penelitian memiliki sistematika yang jelas, disusunlah langkah-langkah penelitian yang dilakukan sebagai berikut.

1. Tahap identifikasi

- melakukan identifikasi masalah, tujuan, dan batasan penelitian;

- studi literatur.

2. Tahap perancangan dan implementasi sistem

- membuat rancangan sistem;

- menyusun spesifikasi sistem;

- membuat desain sistem.

\section{HASIL DAN PEMBAHASAN}

Interaksi yang dirancang adalah interaksi langsung, artinya pengguna secara langsung dapat melakukan manipulasi model virtual yang ada. Interaksi jenis ini diharapkan akan menumbuhkan kesan lebih impresif atau kesan yang mendalam ketika pengguna memakai sistem ini. Diharapkan juga agar saat seseorang yang ingin menggunakan sistem ini, orang tersebut tidak perlu latihan khusus dan dalam waktu yang lama karena interaksi ini adalah apa yang orang tersebut lakukan tiap hari terhadap obyek-obyek nyata.

Adapun desain dari tangan virtual yang digunakan ARAD menyerupai dengan tangan manusia. Perbedaan terletak jumlah jari yang divisualisasikan. Program ARAD hanya menggunakan dua jari, yaitu jempol dan telunjuk. Kebutuhan akan semua jenis interaksi dalam sistem ini dapat dilakukan hanya dengan model dua jari virtual.

Tangan virtual dalam ARAD adalah perangkat virtual tunggal untuk segala masukan (input). Jadi, sistem ini tidak menggunakan keyboard, mouse, atau perangkat masukan lain untuk interaksi selain dari tangan virtual. Hal ini akan memberi kesan lebih dalam terhadap pengguna dan lebih menyerupai seperti di kehidupan nyata.

Model tangan virtual akan tergambar hanya jika tiga marker yang terletak pada tangan terdeteksi oleh ARToolKitPlus. Jika yang terdeteksi kurang dari tiga marker, maka hanya tergambar kotak di atas marker yang terdeteksi.

Untuk dapat berinteraksi dengan model virtual, marker yang terletak di ujung telunjuk dan ujung jempol harus terdeteksi. Karena 2 marker tersebut adalah marker kunci yang didesain selain untuk penggambaran visual tangan namun juga untuk perhitungan interaksi. Penataan marker pada tangan manusia dapat dilihat seperti dalam Gambar 5.

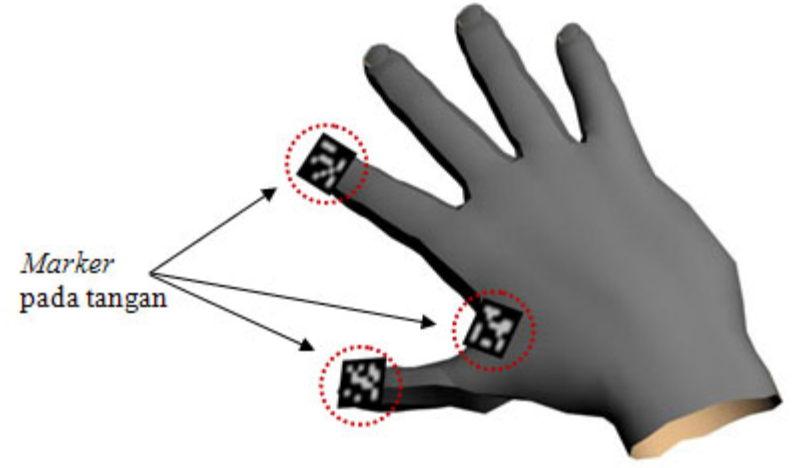

Gambar 5. Letak marker pada tangan.

Seperti yang terlihat dalam Gambar 5, marker diletakkan pada ujung jari telunjuk dan pangkal telunjuk. Agar lebih tampak sesuai dengan jari manusia, maka ditetapkan beberapa asumsi. Asumsi pertama adalah jari telunjuk hanya mempunyai 1 sendi, yaitu yang terdekat dengan 
pangkal jari telunjuk. Asumsi kedua adalah jari jempol tidak mempunyai persendian antara pangkal dan ujung jari jempol. Dengan asumsi ini, sifat realistis tetap dapat tercapai. Untuk lebih jelasnya, dapat dilihat dalam Gambar 6.

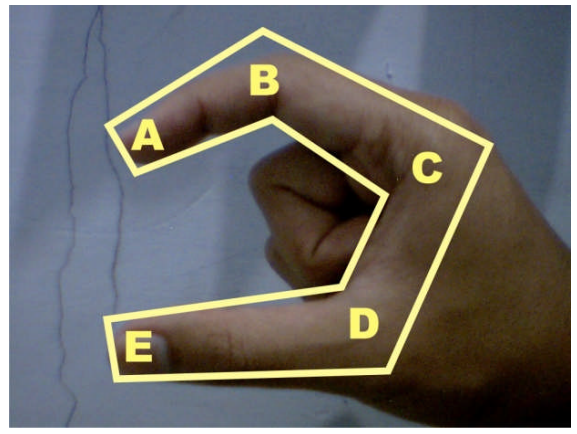

Gambar 6. Titik-titik persendian agar tangan virtual tampak lebih realistis.

Penjelasan gambar:

- titik $\mathrm{A} \rightarrow$ relatif terhadap titik $\mathrm{C}$,

- titik $B \rightarrow$ buku jari/sendi, relatif terhadap jarak antara titik $A$ dan $E$, absolut terhadap titik C,

- titik $C \rightarrow$ relatif terhadap dirinya sendiri,

- titik $\mathrm{D} \rightarrow$ absolut terhadap titik $\mathrm{C}$,

- titik $\mathrm{E} \rightarrow$ relatif terhadap titik $\mathrm{C}$.

Dalam menggambar tangan virtual, yang menjadi titik utama penggambaran adalah titik $C$. Karena titik $A$ dan titik $E$ relatif terhadap titik $C$ maka panjang $A-B$ dan $E-D$ dapat memanjang atau memendek sesuai dengan gerakan telunjuk dan jempol. Titik $C$ dipilih sebagai patokan dalam menggambar tangan virtual karena titik $C$ tidak tergantung pada titik lain dan posisinya tetap relatif terhadap titik-titik lain.

Marker yang terletak di ujung jari telunjuk dan jempol dilekatkan oleh plester double tape di sebuah cincin yang terbuat dari kertas untuk memudahkan pengguna dalam memasang pada jari. Ukuran marker yang digunakan adalah $2 \mathrm{~cm}$ dilingkupi oleh area putih dengan lebar $0,5 \mathrm{~cm}$. Ukuran $2 \mathrm{~cm}$ dipakai agar pengguna merasa nyaman untuk berinteraksi karena relatif tidak besar ketika dilekatkan di tangan. Area putih yang melingkupi marker berguna saat marker berada di atas area berwarna gelap atau hitam, sehingga area putih ini dapat mempertegas antara latar marker dan marker itu sendiri.

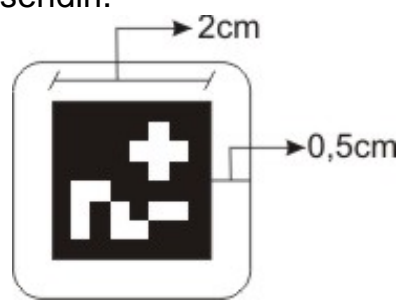

Gambar 7. Desain marker dengan area putih di sekelilingnya.

Jenis interkasi yang diteliti adalah mengambil obyek virtual dan menjatuhkan obyek virtual jenis. Ukuran obyek virtual yang diambil harus lebih kecil dari maksimal renggangan antara jari jempol dan jari telunjuk. Untuk obyek yang berukuran kecil, jenis interkasi yang digunakan hanya mendekatkan jari telunjuk dengan obyek yang berukuran kecil tersebut. Setiap interaksi mempunyai algoritma sendiri.

Beberapa aktifitas dalam manipulasi model adalah mengambil (grabbing) dan menjatuhkan (dropping). Interaksi jenis ini mengharuskan marker yang berada di ujung telunjuk dan ujung jempol terdeteksi oleh ARToolKitPlus. 
Proses pengukuran untuk aktifitas mengambil obyek dan menjatuhkan obyek melibatkan beberapa pengukuran, yaitu berdasarkan jarak antara marker di ujung jari telunjuk dan jempol, jarak antara tangan virtual dengan model virtual, dan jarak antara tangan virtual dan bidang master atau desain. Lebih jelasnya, dapat dilihat dalam Gambar 8.

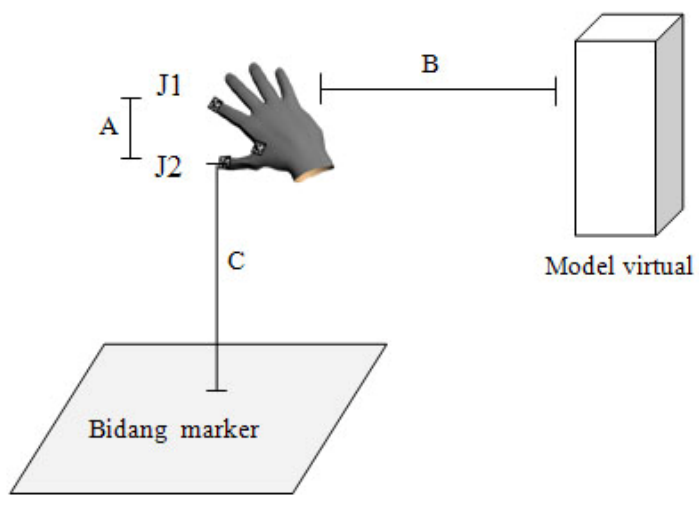

Gambar 8. Perhitungan jarak untuk interaksi.

Keterangan gambar:

- $\quad$ jarak $A \rightarrow$ jarak antara marker di ujung jari telunjuk dan jempol,

- jarak $B \rightarrow$ jarak antara tangan virtual dengan model virtual,

- jarak $\mathrm{C} \rightarrow$ jarak antara tangan virtual dengan bidang master atau desain.

Bidang marker adalah tempat obyek virtua ditempatkan. Bidang marker terdiri dari lebih dari satu marker. Pada penelitian ini, bidang marker dibuat sebanyak 25 marker yang masingmasing marker mempunyai ukuran panjang $\times$ lebar adalah $4 \mathrm{~cm} \times 4 \mathrm{~cm}$. User dapat mengambil obyek virtual yang terletak di bidang marker kemudian menjatuhkan obyek virtual itu juga di bidang marker, diletak yang berbeda.

Masing-masing jenis interaksi akan diterangkan sebagai berikut.

1. Mengambil model.

Mengambil model atau grabbing adalah langkah awal dari menjatuhkan model. Sistem akan masuk dalam status 'ambil' jika dan hanya jika marker yang terletak di ujung telunjuk dan di ujung jempol berada di dalam model virtual.

Berikut ini pseudo code untuk mengambil model:

a. untuk setiap marker J1 dan J2, lakukan pengecekan apakah berada di dalam model virtual,

b. lanjutkan terus terhadap semua model jika status sistem belum 'ambil',

c. cari titik tengah antara $\mathrm{J} 1$ dan $\mathrm{J} 2$ dalam world coordinate,

d. cari rotasi model virtual terhadap sumbu $\mathrm{z}$,

e. cari jarak antara J1 dan J2,

f. cari titik ambil J1 dari atas model virtual.

Selama status sistem masih 'ambil' maka sistem terus me-render model virtual tersebut di titik tengah antara J1 dan J2.

2. Menjatuhkan atau melepaskan model.

Aktifitas ini dikerjakan hanya jika sistem saat ini dalam status 'ambil'. Sistem akan menyatakan bahwa model akan dijatuhkan atau dilepaskan hanya jika jarak sekarang antara marker yang berada di ujung telunjuk dan marker yang berada di ujung jempol lebih besar dari jarak yang tersimpan sebelumnya.

Berikut ini pseudo code untuk menjatuhkan atau melepaskan model:

a. jika jarak antara J1 dan J2 sekarang lebih besar dari jarak J1 dan J2 sebelumnya, maka set status sistem sama dengan 'normal',

b. cari matriks transformasi titik tengah $\mathrm{J} 1$ dan $\mathrm{J} 2$ dengan marker bidang desain,

c. cari sudah berapa derajat model virtual berputar terhadap sumbu z, set atribut dari model virtual dengan nilai hasil perhitungan di atas. 


\section{Menyalin model}

Jenis interaksi menyalin model adalah ketika pengguna ingin memindahkan model dengan dimensi kecil, maka pengguna dapat mengaktifkan mode interaksi menyalin (copy). Interaksi jenis ini hanya membutuhkan marker yang terletak di ujung jari telunjuk (sama seperti jenis interaksi menekan tombol dan manipulasi jalan). Untuk mengaktifkan mode ini, pengguna dapat menekan tombol yang mempunyai tekstur khusus. Kemudian dengan menggunakan jari telunjuk, marker didekatkan dengan model yang ingin diambil. Setelah berhasil diambil, pengguna mengarahkan model tersebut ke tempat yang diinginkan dan memiringkan marker terhadap sumbu $x$ atau y sebesar $180^{\circ}$ agar model tersebut jatuh.

Berikut ini pseudo code untuk menyalin model:

a. untuk setiap marker J1, lakukan pengecekan apakah berada di dalam model virtual,

b. lanjutkan terus pengecekan sampai status sistem sama dengan 'salin',

Jika marker bidang desain model terdeteksi, maka lanjutkan ke pseudo code berikut ini untuk menjatuhkan model:

c. cari $\theta$ besar sudut antara J1 dan bidang desain model,

d. jika $\mathrm{J} 1$ membentuk sudut $>180^{\circ}$ maka model jatuh,

e. cari matriks transformasi $\mathrm{J} 1$ relatif terhadap bidang desain,

f. simpan matriks translasi dari hasil perhitungan di atas sebagai matriks translasi model virtual baru,

g. set status sistem sama dengan 'normal'.

\section{KESIMPULAN}

Tangan virtual dirancang dengan menggunakan jenis interaksi langsung dan alamiah. Tangan virtual ini dirancang dengan memanfaatkan 3 marker sebagai patokan dalam menggambar tangan virtual. Ukuran ketiga marker tersebut adalah $2 \mathrm{~cm}$ berbentuk bujursangkar. Marker dikelilingi oleh area putih sebagai pembeda yang jelas antara marker dan latar disekitarnya. Dengan adaya area putih akan menyebabkan marker akan terlihat jelas saat ditangkap oleh kamera atau webcam.

Tangan virtual ini dirancang hanya menggunakan dua jari virtual untuk berinteraksi dengan sistem. Kebutuhan dasar interaksi, seperti mengambil obyek virtual dan menekan tombol virtual dapat dilakukan hanya dengan 2 jari virtual saja.

Untuk berinterkasi dengan obyek virtual, dibutuhkan beberapa pengukuran, yaitu berdasarkan jarak antara marker di ujung jari telunjuk dan jempol, jarak antara tangan virtual dengan model virtual, dan jarak antara tangan virtual dan bidang master atau desain. 


\section{DAFTAR PUSTAKA}

Andriansyah M., (2008), "Perancangan Augmented Reality Of Residential Area Design Yang Didukung Computer Supported Cooperative Work untuk Developer", STEI, ITB, Bandung.

Dünser, Andreas et al., (2004), "Applying HCl Principles to AR Systems Design", HIT Lab NZ, University of Canterbury, New Zealand.

H. Kaufmann: "Geometry Education with Augmented Reality"; Reviewer: D. Schmalstieg, M. Wagner, M. Billinghurst; Institut für Softwartechnik und Interaktive Systeme, 2004.

Buchmann, Volkert et al., (2004), "FingARtips - Gesture Based Direct Manipulation in Augmented Reality", HitLabNZ, New Zealand.

Shahzad, Malik, (2002), "Robust Registration of Virtual Objects for Real-Time Augmented Reality", Thesis, The Ottawa-Carleton Institute for Computer Science, Canada.

Gibet, S., et al., (2006), Gesture in Human Computer Interaction and Simulation. Berlin, Heidelberg, and New York: Springer.

Dünser, Andreas et al., (2004), "Applying HCl Principles to AR Systems Design", HIT Lab NZ, University of Canterbury, New Zealand.

Ledermann, F., (2004), "An Authoring Framework for Augmented Reality Presentations", Master's thesis, Vienna University of Technology.

Wikipedia Online, http://en.wikipedia.org/wiki/Computer_vision, 2 Pebruari 2013, 12:47 WIB.

Kato, Hirokazu, (2000), ARToolKit 2.33, http://www.tinmith.net/lca2004/ARToolkit/ARToolKit2.33doc.pdf, diakses tanggal 05 Juli 2008, 13:00 WIB.

Kato, Hirokazu, (2000), ARToolKit 2.33, http://www.tinmith.net/lca2004/ARToolkit/ARToolKit2.33doc.pdf, diakses tanggal 05 Juli 2008, 13:00 WIB. 